\title{
Integrated Treatment during the Intravitreal Melphalan Era: Concurrent Intravitreal Melphalan and Systemic Chemoreduction
}

\author{
Jesse L. Berry ${ }^{a, b}$ Sona Shaha, b Fiona Kimª, ${ }^{a}$ Rima Jubran ${ }^{c} \quad$ Jonathan W. Kimª, b \\ a USC Roski Eye Institute, Los Angeles, CA, USA; ${ }^{b}$ The Vision Center at Children's Hospital Los Angeles, Los Angeles, CA, \\ USA; 'The Children's Center for Cancer and Blood Diseases, Children's Hospital Los Angeles, Los Angeles, CA, USA
}

\section{Established Facts}

- Seeding is a common cause of retinoblastoma relapse.

- Intravitreal melphalan is an effective strategy for treating vitreous seeding.

\section{Novel Insights}

- Concurrent systemic chemoreduction and intravitreal melphalan may be a strategy for effective therapy while minimizing the number of examinations under anesthesia required.

- Intravitreal injection of melphalan-associated toxicity and whether there is additional toxicity with this approach require further research.

\section{Keywords}

Retinoblastoma · Chemotherapy · Intravitreal injection ·

Melphalan · Treatment outcomes

\begin{abstract}
Background: Intravitreal injection of melphalan (IVM) is safe and effective for the treatment of seeding in retinoblastoma. Current protocols require weekly injections during examination under anesthesia (EUA). To avoid additional anesthesia exposure for these children, IVM was initiated at the EUA concurrent with the 4th cycle of systemic chemoreduction in a series of 6 patients with persistent seeding. Methods: A retrospective review was completed to assess treatment response compared to all patients at our center treated with
\end{abstract}

IVM and systemic chemotherapy. Overall, 6 eyes of 6 patients were included; salvage therapy included systemic chemoreduction with vincristine, etoposide, and carboplatin and IVM for persistent seeding. Results: IVM was initiated in all eyes at cycle 4 of their chemotherapy. Success in eradicating vitreous seeds was $100 \%$; overall salvage rate was $67 \%$. Anterior toxicity was observed in 2 out of 6 eyes and posterior toxicity in 4 out of 6 eyes. Conclusion: The concurrent chemoreduction and IVM protocol demonstrated a similar efficacy of globe salvage while sparing children additional EUAs. However, the increased rates of observed melphalan-related toxicities for concurrent therapy are concerning. Further clinical experience is necessary to define the best initiation time and dosing schedule for IVM.

(c) 2018 S. Karger AG, Basel

\section{KARGER}

(c) 2018 S. Karger AG, Basel

E-Mail karger@karger.com

www.karger.com/oop
Jesse L. Berry, MD

USC Roski Eye Institute

1450 San Pablo Street

Los Angeles, CA 90033 (USA)

E-Mail jesse.berry@med.usc.edu 


\section{Introduction}

Salvage of retinoblastoma eyes has historically been limited by the presence of seeds, which consist of small tumor foci in the vitreous and subretinal space that can result in multiple new tumors, tumor relapse, and subsequent loss of the eye [1-3]. The advent of a safe and efficacious method for delivering intravitreal injection of melphalan (IVM) has revolutionized the current approach for treating seeding in advanced retinoblastoma [4]. Previous reports on the efficacy of intravitreal melphalan demonstrate $100 \%$ success in eradicating vitreous seeding and high globe salvage rates of $68-86 \%$ on par with rates previously attained with external beam radiation therapy [5-10].

While success rates are encouraging, the exact timing, dosage, and number of injections is still under review. Currently, no "gold standard" of care has been defined for intravitreal chemotherapy in the same way that norms exist for systemic and intra-arterial chemotherapy. One hypothesis is to combine therapy and initiate concurrent IVM with cycles 4-6 of systemic chemotherapy. This approach has the potential benefit of providing synergistic antineoplastic effects against vitreous seeds while decreasing the overall number of examinations under anesthesia (EUA) that these children experience, given that IVM after systemic chemoreduction often requires 3 or more weekly injections $[5,6]$.

In this case series, we examine the results of 6 patients diagnosed with advanced retinoblastoma with persistent vitreous seeding during chemoreduction who were treated with concurrent IVM injections with the last 3 cycles of systemic chemoreduction. The main outcome measure was event-free globe survival. The secondary objective was to compare the efficacy and toxicity to previous studies wherein IVM was initiated after systemic chemoreduction (e.g., sequential therapy).

\section{Methods}

We conducted a retrospective chart review of patients diagnosed with retinoblastoma at the Children's Hospital Los Angeles (CHLA) from 2014 to 2017. Patients who received concurrent intravitreal melphalan and systemic chemoreduction for persistent seeding were included. The Institutional Review Board approved this study.

The treatment protocol for retinoblastoma at CHLA has previously been published $[11,12]$. The injection procedure closely adheres to the protocol outlined by Munier and colleagues [13-15] and previously published [6]. Although a standardized dosage of melphalan has not been fully established due to the relative nov- elty of the treatment modality, previous publications support the usage of 20-40 $\mu \mathrm{g}$. After Francis et al.'s [16] report of electroretinogram amplitude decrease after $30 \mu \mathrm{g}$ of melphalan, IVM dosing was limited to maximally $30 \mu \mathrm{g}$; at our center, $25 \mu \mathrm{g}$ is the most frequently used dose with modifications made for the clinical burden of seeding.

For the concurrent IVM injection protocol, follow-up EUA and injection were performed at 4-week intervals on the same day as administration of systemic chemoreduction. This protocol was utilized for patients with persistently active vitreous seeding diagnosed after 3 cycles of systemic chemotherapy, with patients receiving IVM on the same day as the 4 th, 5 th, and 6 th cycles of chemoreduction. For persistent or recurrent seeding diagnosed after the completion of systemic chemoreduction, another series of weekly injections was performed following the previously described protocol $[5,6]$. One patient received 5 total injections within cycles 4-6 of chemotherapy.

Eyes were classified according to the International Intraocular Retinoblastoma Classification (IIRC) System outlined by Linn Murphree [17] and the seeding classification outlined by Munier [14] and Francis et al. [7, 18].

A retrospective chart review was completed to obtain age at diagnosis, gender, laterality, genetic testing status, length of follow-up, dose and number of intravitreal injections, and clinical response to injection.

\section{Results}

Demographic and management details of each case are provided in Table 1. Comparisons to the larger previously published cohort, which included 28 eyes receiving systemic chemotherapy and IVM [5], are displayed in Table 2 by seed class $[7,14]$. In this group of 28 eyes, 6 eyes demonstrated persistent seeding during systemic chemotherapy. In the current study, all 6 eyes of 6 patients included underwent attempted salvage therapy with concurrent systemic chemoreduction and IVM due to persistent vitreous seeding. A median melphalan dose of $25 \mu \mathrm{g}$ and a median of 3 injections were required similar to the larger cohort of patients. The mean cumulative dose of melphalan was just over $100 \mu \mathrm{g}$ in both groups as well. The median age was slightly older in the concurrent therapy group, and the rate of toxicity was greater. Spherical seeding was only seen in the larger cohort, as this type of seed morphology is described primarily in recurrent cases. Two of 6 eyes required additional IVM therapy after the 3 injections given during chemotherapy. $100 \%$ of eyes showed complete resolution of seeding; however, all eyes also demonstrated some level of toxicity. Three eyes developed grade 3 retinal toxicity, and 1 eye developed grade 4 retinal toxicity. Two eyes developed both a cataract and iris atrophy. Four of the 6 eyes were salvaged. 
Table 1. Patient demographics and results

\begin{tabular}{|c|c|c|c|c|c|c|}
\hline & Patient 1 & Patient 2 & Patient 3 & Patient 4 & Patient 5 & Patient 6 \\
\hline Age at diagnosis, months & 28 & 28 & 22 & 26 & 24 & 13 \\
\hline Sex & $\mathrm{F}$ & $\mathrm{M}$ & $\mathrm{F}$ & $\mathrm{M}$ & $\mathrm{M}$ & $\mathrm{F}$ \\
\hline Eye & OD & OD & OS & OS & OS & OD \\
\hline Group & D2 & D1 & D2 & D1 & D2 & $\mathrm{C}$ \\
\hline Laterality & bilateral & unilateral & unilateral & bilateral & unilateral & bilateral \\
\hline Seed type & cloud & cloud & dust & cloud & dust & dust \\
\hline Cycles with concurrent IVM, $n$ & $4-6$ & $4-6$ & 4 & 4 & $4-6$ & $4-6$ \\
\hline Total injections & 10 & 6 & 2 & 1 & 3 & 3 \\
\hline Postchemo IVM & 7 & 1 & 0 & 0 & 0 & 0 \\
\hline $\begin{array}{l}\text { Median IVM dose (range), } \mu \mathrm{g} \\
\text { Toxicity } \\
\text { Seeding response } \\
\text { Salvage } \\
\text { Reason for enucleation }\end{array}$ & $\begin{array}{l}30(20-30) \\
\text { grade } 3 \mathrm{RPE} \\
\text { changes } \\
\text { resolved } \\
\text { enucleated } \\
\text { recurrence } \\
\text { involving ON }\end{array}$ & $\begin{array}{l}25(20-25) \\
\text { grade } 3 \text { RPE } \\
\text { changes } \\
\text { resolved } \\
\text { yes }\end{array}$ & $\begin{array}{l}20(20) \\
\text { mild cataract, } \\
\text { iris atrophy } \\
\text { resolved } \\
\text { enucleated } \\
\text { recurrence } \\
\text { involving ON }\end{array}$ & $\begin{array}{l}25(25) \\
\text { grade } 3 \mathrm{RPE} \\
\text { changes } \\
\text { resolved } \\
\text { yes }\end{array}$ & $\begin{array}{l}25(25) \\
\text { hydrated cataract, } \\
\text { iris atrophy } \\
\text { resolved } \\
\text { yes }\end{array}$ & $\begin{array}{l}20(20) \\
\text { grade } 4 \mathrm{RPE} \\
\text { changes } \\
\text { resolved } \\
\text { yes }\end{array}$ \\
\hline
\end{tabular}

OD, right eye; OS, left eye; RB1, retinoblastoma gene; q, long arm; p, short arm; IVM, intravitreal injection of melphalan; RPE, retinal pigment epithelium; ON, optic nerve.

\section{Discussion}

This case series reports the outcomes of a small cohort of patients with retinoblastoma at CHLA treated with systemic intravenous chemoreduction and concurrent IVM for persistently active vitreous seeding. Overall, treatment with systemic intravenous chemotherapy, local consolidation, and concurrent IVM resulted in a globe salvage rate of $67 \%$ ( 4 of 6 eyes) at 11.5 months' median follow-up (range 6-29 months). No eyes were enucleated due to progressive vitreous seeding; IVM was $100 \%$ successful in treating vitreous seeding and avoidance of external beam radiation therapy.

A previous series examining all eyes treated with IVM for persistent or recurrent vitreous seeding demonstrated a salvage rate of $68 \%$ with $100 \%$ success of the IVM therapy in eradicating vitreous seeds [5]. The $67 \%$ salvage rate of this case series suggests that concurrent chemotherapy and IVM may be a viable treatment option for patients with persistent seeding. However, there did not seem to be an advantage to concurrent IVM when considering globe salvage rates alone.

A clear benefit to this approach is reduced need for multiple weekly examinations under anesthesia at the end of chemoreduction for additional IVM, although 1 of the cases did require 7 additional injections. All patients in this series received concurrent IVM injections during their already scheduled EUA along with chemotherapy cycles 4-6. Considering the young age of the patients undergoing IVM (median age 25 months, SD 5.6), the reduction of additional anesthesia sessions is an advantage for this patient population [19]. There were no cases of extraocular tumor spread when performing IVM prior to the completion of systemic chemotherapy for advanced retinoblastoma.

Retinal toxicity was determined based on the system delineated by Munier [14] and classified as grade 1-5. In this case series, 3 of 6 eyes developed grade 3 posterior retinal toxicity described as salt-and-pepper retinal pigment epithelial (RPE) changes extending posterior to the equator but sparing the macula. One eye developed grade 4 retinopathy involving the macula. No eye developed grade 5 retinopathy. IVM-related anterior toxicities occurred in 2 of 6 eyes after injection (neither eye had retinal toxicity). In both these eyes, combined cataract and iris atrophy occurred. In comparison, previous data from our center reported grade 3 or higher retinal toxicity and/or anterior segment toxicity, including cataract, focal iris atrophy, and transient anterior segment inflammation developing in about $43 \%$ of patients $[5,6]$. Our data from 
Table 2. Comparison of concurrent intravenous chemotherapy and IVM with results from a prior study of all eyes treated with IVM and intravenous chemotherapy

\begin{tabular}{|c|c|c|c|c|c|c|c|c|}
\hline & \multicolumn{4}{|c|}{$\begin{array}{l}\text { Eyes with concurrent intravenous chemotherapy and } \\
\text { IVM treated at CHLA }\end{array}$} & \multicolumn{4}{|c|}{ Eyes from a previous study completed at CHLA [5] $]^{\mathrm{a}}$} \\
\hline & $\begin{array}{l}\text { class I: } \\
\text { dust }\end{array}$ & $\begin{array}{l}\text { class II: } \\
\text { spheres }\end{array}$ & $\begin{array}{l}\text { class III: } \\
\text { clouds }\end{array}$ & overall & $\begin{array}{l}\text { class I: } \\
\text { dust }\end{array}$ & $\begin{array}{l}\text { class II: } \\
\text { spheres }\end{array}$ & $\begin{array}{l}\text { class III: } \\
\text { clouds }\end{array}$ & overall \\
\hline Eyes, $n$ & 3 & 0 & 3 & 6 & 15 & 8 & 5 & 28 \\
\hline \multicolumn{9}{|l|}{ Injections, $n$} \\
\hline Median & 3 & & 6 & 3 & 3 & 4 & 6 & 3 \\
\hline Range & $2-3$ & & $1-10$ & $1-10$ & $1-6$ & $3-8$ & $1-10$ & $1-10$ \\
\hline \multicolumn{9}{|l|}{ Melphalan dose, $\mu \mathrm{g}$} \\
\hline Median & 20 & & 25 & 25 & 25 & 25 & 30 & 25 \\
\hline Mean & 21.9 & & 26.3 & 24.1 & 27.7 & 26.9 & 29.9 & 8 \\
\hline Range & $20-25$ & & $20-30$ & $20-30$ & $20-40$ & $20-40$ & $20-40$ & $20-40$ \\
\hline \multicolumn{9}{|l|}{ Cumulative melphalan, $\mu \mathrm{g}$} \\
\hline Median & 24 & & 31 & 28 & 16 & 16 & 29 & 21 \\
\hline Mean & 22.3 & & 30.3 & 26.3 & 20 & 20 & 26 & 17 \\
\hline Range & $16-27$ & & $29-31$ & $16-31$ & $6-73$ & $9-33$ & $14-31$ & $6-72$ \\
\hline$\%$ complications/toxicity & $(3 / 3)=100 \%$ & & $(3 / 3)=100 \%$ & $(6 / 6)=100 \%$ & $(4 / 15)=27 \%$ & $(4 / 8)=50 \%$ & $(4 / 5)=80 \%$ & $(12 / 28)=43 \%$ \\
\hline$\%$ enucleated & $(1 / 3)=33 \%$ & & $(1 / 3)=33 \%$ & $(2 / 6)=33 \%$ & $(5 / 15)=33 \%$ & $(2 / 8)=25 \%$ & $(2 / 5)=40 \%$ & $(9 / 28)=32 \%$ \\
\hline \multicolumn{9}{|l|}{$\%$ enucleated owing to } \\
\hline Seeding regression & $100 \%$ & & $100 \%$ & $100 \%$ & $100 \%$ & $100 \%$ & $100 \%$ & $100 \%$ \\
\hline \multicolumn{9}{|l|}{ Ocular survival owing to } \\
\hline active tumor & $67 \%$ & & $67 \%$ & $67 \%$ & $73 \%$ & $100 \%$ & $60 \%$ & $79 \%$ \\
\hline Overall ocular survival & $67 \%$ & & $67 \%$ & $67 \%$ & $67 \%$ & $75 \%$ & $60 \%$ & $68 \%$ \\
\hline
\end{tabular}

IVM, intravitreal injection of melphalan; CHLA, Children's Hospital Los Angeles. ${ }^{\text {a }}$ This study demonstrates outcomes of intravenous chemotherapy with IVM for persistent or recurrent seeds.

this small case series reflect higher rates of toxicity than previously demonstrated by our center, which examined all patients who received IVM with systemic chemoreduction. This increased toxicity could be attributed to the fact that IVM and systemic chemoreduction were administered concurrently to the posterior segment at therapeutic doses. Another possibility includes the advanced presentation of these patients with persistent seeding that did not respond to chemotherapy alone, which necessitated earlier intervention of melphalan and concurrent therapy and, therefore, made them potentially more prone to developing higher rates of toxicity regardless of management.

It is important to note that unlike intra-arterial chemotherapy [20], systemic chemotherapy alone has not been associated with retinal toxicity [21]. Intravitreal delivery of chemotherapy is not without its own set of side effects, including retinal toxicity as described by Munier [14]. Suzuki et al. [22] reported findings for anterior toxicity, including iris atrophy and dense cataracts, in $8.7 \%$ of eyes $(23 / 264)$ and diffuse chorioretinal atrophy in $0.8 \%$ of eyes (2/264). Ghassemi and Shields [23] reported RPE changes, cataracts, and phthisis in $25 \%$ of eyes (3/12). Munier et al. [24] described a localized retinal toxicity rate of $43 \%$ (10/26 eyes), and Tuncer et al. [8] reported a rate of 39\% (2/7) for RPE mottling at the site of injections. A recent study by Kiratli et al. [25] reported vitreous hemorrhage in $18 \%$ of injected eyes (7/39) and "widespread" RPE changes in $8 \%$ of eyes $(3 / 39)$. While the grading system proposed by Munier [14] was not used in this (and other) 
studies, "widespread" likely indicates at least greater than grade 3. It has been suggested that doses $>30 \mu \mathrm{g}$ may increase toxicity [16], although acute and diffuse toxicity have been described recently by Chao et al. [26] after only 1 low-dose injection and by Aziz et al. [27] at doses lower than $30 \mu \mathrm{g}$. Although our study observed a higher rate of retinal toxicity than prior ocular oncology literature, our cohort is small, and, additionally, the variation in the determination of retinal toxicity limits any direct comparison with the clinical grading we utilized as proposed by Munier [14]. While prior studies reported "diffuse" or "widespread" RPE changes, our study reports greater than grade 3 toxicity. Nevertheless, while this new treatment protocol may reduce the frequency of EUAs, the higher rates of toxicity are a potential concern, and further research with a larger cohort of patients is required.

Our report describes a small series of patients treated for advanced retinoblastoma with vitreous seeding who received primary chemotherapy and concurrent IVM injections initiated with cycle 4 of chemotherapy. Our review demonstrates an overall globe salvage rate of $67 \%$, which is comparable to the $68 \%$ salvage rate we reported for all patients treated with systemic chemotherapy and intravitreal chemotherapy [5]. More research and clinical experience is necessary to better define the best time to initiate intravitreal injections for vitreous seeding, as well as the optimal number and dosing schedule for IVM. The strategy of delivering concurrent IVM and systemic chemotherapy has the advantage of sparing children additional EUAs, although there did not appear to be an advantage for improving globe salvage rates in this small series. There was also an increased rate of ocular toxicity; however, the small size of the cohort limits any definitive conclusions. As ocular oncology centers continue to utilize this treatment for seeding, it is important to develop a consensus regarding the optimal way to integrate IVM into current chemotherapy regimens to optimize globe salvage results while minimizing associated toxicities.

\section{Statement of Ethics}

The Institutional Review Board approved this study.

\section{Disclosure Statement}

The authors declare that there is no conflict of interest. No conflicting relationship exists for any author.

\section{Funding Sources}

This study was supported by the Institute for Families, Inc., the Larry and Cecilia Moh Foundation, and Research to Prevent Blindness.

\section{References}

1 Gallie BL, Budning A, DeBoer G, Thiessen JJ, Koren G, Verjee Z, Ling V, Chan HS: Chemotherapy with focal therapy can cure intraocular retinoblastoma without radiotherapy. Arch Ophthalmol 1996;114:1321-1328.

-2 Murphree AL, Villablanca JG, Deegan WF, Sato JK, Malogolowkin M, Fisher A, Parker R, Reed E, Gomer CJ: Chemotherapy plus local treatment in the management of intraocular retinoblastoma. Arch Ophthalmol 1996;114: 1348-1356.

3 Manjandavida FP, Shields CL: The role of intravitreal chemotherapy for retinoblastoma. Indian J Ophthalmol 2015;63:141-145.

-4 Munier FL, Soliman S, Moulin AP, Gaillard MC, Balmer A, Beck-Popovic M: Profiling safety of intravitreal injections for retinoblastoma using an anti-reflux procedure and sterilisation of the needle track. Br J Ophthalmol 2012;96:1084-1087.
5 Berry JL, Bechtold M, Shah S, Zolgaghari E, Reid M, Jubran R, Kim JW: Not all seeds are created equal: seed classification is predictive of outcomes in retinoblastoma. Ophthalmology 2017;124:1817-1825.

6 6 Berry JL, Shah S, Bechtold M, Zolfaghari E, Jubran R, Kim JW: Long-term outcomes of Group D retinoblastoma eyes during the intravitreal melphalan era. Pediatr Blood Cancer 2017, DOI: 10.1002/pbc.26696.

7 Francis JH, Abramson DH, Gaillard MC, Marr BP, Beck-Popovic M, Munier FL: The classification of vitreous seeds in retinoblastoma and response to intravitreal melphalan. Ophthalmology 2015;122:1173-1179.

8 Tuncer S, Balci O, Tanyildiz B, Kebudi R, Shields CL: Intravitreal lower-dose $(20 \mathrm{mi}-$ crog) melphalan for persistent or recurrent retinoblastoma vitreous seeds. Ophthalmic Surg Lasers Imaging Retina 2015;46:942-948.

-9 Shields CL, Manjandavida FP, Arepalli S, Kaliki S, Lally SE, Shields JA: Intravitreal melphalan for persistent or recurrent retinoblastoma vitreous seeds: preliminary results. JAMA Ophthalmol 2014;132:319-325.
10 Shields CL, Douglass AM, Beggache M, Say EA, Shields JA: Intravitreous chemotherapy for active vitreous seeding from retinoblastoma: outcomes after 192 consecutive injections. The 2015 Howard Naquin Lecture. Retina 2016;36:1184-1190.

11 Berry JL, Jubran R, Kim JW, Wong K, Bababeygy SR, Almarzouki H, Lee TC, Murphree AL: Long-term outcomes of Group D eyes in bilateral retinoblastoma patients treated with chemoreduction and low-dose IMRT salvage. Pediatr Blood Cancer 2013;60:688-693.

-12 Berry JL, Jubran R, Lee TC, Murphree AL, Lee D, Kim JW: Low-dose chemoreduction for infants diagnosed with retinoblastoma before 6 months of age. Ocul Oncol Pathol 2015; 1: 103-110.

13 Munier FL, Gaillard MC, Balmer A, BeckPopovic M: Intravitreal chemotherapy for vitreous seeding in retinoblastoma: recent advances and perspectives. Saudi J Ophthalmol 2013;27:147-150.
Concurrent Intravitreal and Systemic

Chemotherapy for Retinoblastoma
Ocul Oncol Pathol 2018;4:335-340 DOI: $10.1159 / 000486098$ 
14 Munier FL: Classification and management of seeds in retinoblastoma. Ellsworth Lecture Ghent August 24th 2013. Ophthalmic Genet 2014;35:193-207.

15 Aziz HA, Kim JW, Munier FL, Berry JL: Acute hemorrhagic retinopathy following intravitreal melphalan injection for retinoblastoma: a report of two cases and technical modifications to enhance the prevention of retinal toxicity. Ocul Oncol Pathol 2017;3:34-40.

16 Francis JH, Schaiquevich P, Buitrago E, Del Sole MJ, Zapata G, Croxatto JO, Marr BP, Brodie SE, Berra A, Chantada GL, Abramson DH: Local and systemic toxicity of intravitreal melphalan for vitreous seeding in retinoblastoma: a preclinical and clinical study. Ophthalmology 2014;121:1810-1817.

17 Linn Murphree A: Intraocular retinoblastoma: the case for a new group classification. Ophthalmol Clin North Am 2005;18:41-53.

18 Francis JH, Marr BP, Abramson DH: Classification of vitreous seeds in retinoblastoma: correlations with patient, tumor, and treatment characteristics. Ophthalmology 2016; 123:1601-1605.
19 Ko WR, Huang JY, Chiang YC, Nfor ON, Ko PC, Jan SR, Lung CC, Chang HC, Lin LY, Liaw YP: Risk of autistic disorder after exposure to general anaesthesia and surgery: a nationwide, retrospective matched cohort study. Eur J Anaesthesiol 2015;32:303-310.

20 Francis JH, Abramson DH, Gobin YP, Marr BP, Dunkel IJ, Riedel ER, Brodie SE: Electroretinogram monitoring of dose-dependent toxicity after ophthalmic artery chemosurgery in retinoblastoma eyes: six year review. PLoS One 2014;9:e84247.

21 Bartuma K, Pal N, Kosek S, Holm S, All-Ericsson C: A 10-year experience of outcome in chemotherapy-treated hereditary retinoblastoma. Acta Ophthalmol 2014;92:404-411.

22 Suzuki S, Aihara Y, Fujiwara M, Sano S, Kaneko A: Intravitreal injection of melphalan for intraocular retinoblastoma. Jpn J Ophthalmol 2015;59:164-172.
23 Ghassemi F, Shields CL: Intravitreal melphalan for refractory or recurrent vitreous seeding from retinoblastoma. Arch Ophthalmol 2012;130:1268-1271.

24 Munier FL, Gaillar MC, Balmer A, Soliman S, Podilsky G, Moulin A, Beck-Popovic M: Intravitreal chemotherapy for vitreous disease in retinoblastoma revisited: from prohibition to conditional indications. $\mathrm{Br}$ J Ophthalmol 2012;96:1078-1083.

25 Kiratli H, Koc I, Varan A, Akyuz C: Intravitreal chemotherapy in the management of vitreous disease in retinoblastoma. Eur J Ophthalmol 2017;26:423-427.

26 Chao A, Kao LY, Liu L, Wang NK: Diffuse chorioretinal atrophy after a single standard low-dose intravitreal melphalan injection in a child with retinoblastoma: a case report. BMC Ophthalmol 2016;15:27.

27 Aziz HA, Kim JW, Munier FL, Berry JL: Acute hemorrhagic retinopathy following intravitreal melphalan injection for retinoblastoma: a report of two cases and technical modifications to enhance the prevention of retinal toxicity. Ocul Oncol Pathol 2017;3:34-40. 